\title{
CURRÍCULOS PRESCRITOS EM PROJETOS SOCIAIS VINCULADOS ÀS ATIVIDADES FÍSICAS E ESPORTIVAS
}

Recebido em: 13/10/2020

Aprovado em: 09/05/2021

Licença:@) @ @

\author{
Cássia dos Santos Gonçalves ${ }^{1}$ \\ Universidade Federal do Espírito Santo (UFES) \\ Vitória - ES - Brasil \\ Rodrigo Lema Del Rio Martins ${ }^{2}$ \\ Universidade Federal Rural do Rio de Janeiro (UFRRJ) \\ Seropédica - RJ - Brasil \\ André da Silva Mello ${ }^{3}$ \\ Universidade Federal do Espírito Santo (UFES) \\ Vitória - ES - Brasil
}

RESUMO: Analisa os documentos institucionais de três projetos sociais e de um Serviço de Convivência e Fortalecimento de Vínculos (SCFV), a fim de compreender os modos como as atividades físicas/esportivas estão organizadas nesses contextos. Tratase de uma pesquisa documental, na qual empregamos uma análise descritivointerpretativa para examinar criticamente os documentos institucionais orientadores das práticas pedagógicas. Os dados apontam para o desenvolvimento de aspectos morais e éticos dos participantes, para a valorização da autonomia e do protagonismo dos sujeitos, bem como para questões sociais mais amplas, como a cidadania, o combate ao racismo, a preservação da cultura popular e a importância da educação ambiental. Uma das principais fragilidades encontradas nos documentos analisados é de natureza procedimental e está circunscrita na imprecisão de como as atividades físicas e esportivas serão trabalhadas para atingir os objetivos propostos.

PALAVRAS-CHAVE: Projetos Sociais. Atividades Físico-Esportivas. Documentos. Orientadores.

\section{CURRICULUMS PRESCRIBED IN SOCIAL PROJECTS LINKED TO PHYSICAL AND SPORTS ACTIVITIES}

\footnotetext{
${ }^{1}$ Mestranda em Educação Física pela UFES. Professora da Escola Técnica Municipal de Teatro, Dança e Música (FAFI). Membro do Núcleo de Aprendizagens com as Infâncias e seus Fazeres (NAIF)

${ }^{2}$ Doutor em Educação Física. Professor da Universidade Federal Rural do Rio De Janeiro (UFRRJ). Líder do Núcleo de Aprendizagens com as Infâncias e seus Fazeres (NAIF)

${ }^{3}$ Professor do Programa de Pós-Graduação em Educação Física (PPGEF) da UFES. Líder do Núcleo de Aprendizagens com as Infâncias e seus Fazeres (NAIF/UFES).
} 1 


\begin{abstract}
The paper analyzes the institutional documents derived from three social projects and from a Living the Service and Strengthening Linkages (Serviço de Convivência e Fortalecimento de Vínculos (SCFV), in order to understand how the physical/sports activities are organized within these contexts. It is a documental research, in which a descriptive-interpretative analysis was used to critically examine the institutional policy documents of pedagogical practices. Data point to the development of moral and ethical aspects of the participants, to the appreciation of autonomy and the protagonism of the ones involved, as well as to wider social issues, such as, citizenship, the fight against racism, the preservation of popular culture and the importance of environmental education. One of the main weaknesses found in the analyzed documents has a procedural nature and is circumscribed in the inaccuracy of how physical and sports activities will be performed to achieve the proposed goals.
\end{abstract}

KEYWORDS: Social Projects. Physical-Sports Activities. Guiding. Documents.

\title{
Introdução
}

Pesquisas na área da Educação Física que se interessam por temáticas vinculadas aos projetos sociais não são recentes, porém, se mantém atuais. Em artigos de revisão realizados por Kravchychyn e Oliveira (2015), Mello e outros (2016) e Caron; Marchi Júnior e Silva (2018) verificamos ampla expansão dos projetos e programas que ofertam atividades físicas e esportivas no país, acarretando crescente interesse acadêmicocientífico do campo da Educação Física por essa temática.

A proliferação de projetos sociais que se utilizam das atividades físicas e esportivas ocorreu a partir da década de 1980, em contextos de vulnerabilidade social, com o intuito de complementar ou suprir as carências da educação formal (ZALUAR, 1994). Desde então, os projetos sociais veem se estabelecendo em comunidades periféricas dos centros urbanos, com foco nas infâncias e nas juventudes em situação de risco social. As atividades físicas e esportivas, em especial essas últimas, são revestidas por uma metalinguagem axiológica positiva (DaCOSTA, 2009), que atribuí valores socialmente positivos às práticas esportivas. Nesse sentido, tais atividades são concebidas, sobretudo pelas políticas públicas de esporte e lazer, como panaceia para as mazelas sociais. 
Compreendemos que as atividades físicas e esportivas, quando inseridas nos projetos sociais, podem cumprir uma função “[...] equalizadora uma vez que, ao reconhecer a má distribuição dos bens sociais (tal qual a educação), propõe-se a, tratando de forma diferenciada àqueles/as que são diferentes, colocá-lo/as em condição de igualdade [...]" (CARDOZO, 2017, p. 141).

Para além da necessidade de estudos empíricos que, de fato, comprovem a eficácia das atividades físicas e esportivas no desenvolvimento de valores sociais positivos, também é preciso pesquisas que investiguem o que está sistematizado nos documentos orientadores dos projetos sociais, que aqui estamos denominando de currículos prescritos, analisando as suas intenções e as possibilidades de materialização, por meio da organização e sistematização das práticas pedagógicas presentes nesses documentos.

A partir da premissa de que os currículos da educação formal buscam orientar as ações pedagógicas de ensino, constituindo-se em documentos norteadores das práticas escolares, podemos inferir que os documentos institucionais dos serviços e projetos sociais têm funções similares. Embora não sejam denominados de currículos ou organizações curriculares, esses documentos apresentam os valores, objetivos, estrutura da gestão e de seus associados e, em alguns casos, especificam as atividades (oficinas) a serem desenvolvidas pela instituição.

Vale salientar que não tomamos o currículo prescrito 4 comoo único documento responsável pela regulação socioeducativa, consideramos de suma importância o currículo vivido, que é construído diariamente nas práticas dos educadores com os atendidos, das relações entre os profissionais de cada instituição e desses com a

\footnotetext{
${ }^{4}$ Para Sacristán (2000), o currículo prescrito representa a organização textual de todos os elementos que atuam como referência na ordenação de um determinado percurso operacional com aspirações formativas. Trata-se, portanto, de um documento que serve como ponto de partida para se pensar as ações subjacentes os processos de ensino-aprendizagem, a elaboração de materiais, procedimentos avaliativos etc.
} 
comunidade. No entanto, neste estudo, focalizamos a organização documental para compreender os currículos prescritos e o papel das atividades físicas e esportivas nos projetos sociais.

Ampliar a discussão sobre currículos em projetos sociais pode contribuir para a sistematização e atualização documental das instituições, assim como incentivar a busca por orientações e práticas socioeducativas cada vez mais contextualizadas. Essa ação pode beneficiar os atendimentos às comunidades, como também viabilizar melhorias na apresentação da instituição à possíveis parceiros colaboradores, fortalecendo, dessa forma, a associação entre o público e o privado.

Ao estabelecermos como objeto de estudo o "currículo prescrito" em projetos sociais, buscamos responder as seguintes questões: quais são as especificidades dos projetos analisados? O que eles têm em comum? Os documentos analisados apresentam meios para atingir os objetivos propostos? Quais são as suas principais lacunas?

Para responder a essas questões, este estudo tem como objetivo analisar os documentos institucionais de três projetos sociais e de um Serviço de Convivência e Fortalecimento de Vínculos (SCFV), ${ }^{5}$ localizados na região metropolitana da Grande Vitória - ES, a fim de compreender os modos como as atividades físicas e esportivas estão sistematizadas nesses documentos, com foco nos objetivos propostos e nos meios para alcançá-los.

\section{Metodologia}

Trata-se de um estudo qualitativo, de natureza documental. Neste estudo utilizamos como fontes documentos primários, que não trazem impressões de outras

\footnotetext{
${ }^{5}$ Os SCFVs são financiados e orientados pelo Sistema Único de Assistência Social (SUAS), portanto, trata-se de uma política pública de atendimento socioeducacional. Já os projetos sociais selecionados são organizações de direito privado e são autogeridos. A escolha pela Região Metropolitana da Grande Vitória/ES como lócus de pesquisa, justifica-se pela acessibilidade dos pesquisadores às instituições analisadas e pelas características sociodemográficas semelhantes entre os públicos-alvo atendidos.
} 
análises, pois encontram-se em estado original. O homem, na condição de sujeito histórico e social, deixa vestígios em tudo o que toca e produz, por isso, concordamos com Bloch (2001, p. 79) quando afirma que "[...] tudo o que o homem diz ou escreve, tudo o que fabrica, tudo o que toca pode e deve informar sobre ele". Entretanto, para o autor, cabe ao pesquisador fazer esses "dados falarem”, por meio de processos analíticos e interpretativos que buscam a verossimilhança com a realidade do objeto de estudo.

Sendo assim, a partir da análise dos documentos institucionais, entendidos como currículos prescritos, permitem ao pesquisador compreender os modos como as atividades físicas e esportivas estão sistematizadas nesses documentos, com foco nos objetivos propostos e nos meios para alcançá-los.

Para a escolha das instituições analisadas neste estudo, foram adotados os seguintes critérios de inclusão: o tempo de existência mínimo de 10 anos; ofertar atividades físico e esportivas, estarem localizadas na região da Grande Vitória/ES e; atender no contraturno escolar. Por meio desses critérios, escolhemos quatro instituições, cujas características centrais são apresentadas no Quadro 1:

\section{Quadro 1: Caracterização institucional geral}

\begin{tabular}{|c|c|c|c|c|c|}
\hline Instituições & $\begin{array}{c}\text { Ano de } \\
\text { fundação }\end{array}$ & Localização & Documento analisado & Atividades ofertadas & Unidades \\
\hline $\begin{array}{c}\text { Instituição } \\
\text { A }\end{array}$ & 1992 & Vila Velha & Estatuto social & $\begin{array}{l}\text { Capoeira, música, } \\
\text { artes, recreação } \\
\text { esportiva, panificação, } \\
\text { reforço escolar e } \\
\text { demais atividades } \\
\text { livres quando recebem } \\
\text { voluntários. }\end{array}$ & 1 \\
\hline $\begin{array}{c}\text { Instituição } \\
\text { B }\end{array}$ & 1994 & $\begin{array}{c}\text { Vitória, } \\
\text { Cariacica, } \\
\text { Fundão, } \\
\text { Guarapari e } \\
\text { Viana. }\end{array}$ & Estatuto social & Capoeira & 15 \\
\hline
\end{tabular}




\begin{tabular}{|c|c|c|c|c|c|}
\hline $\begin{array}{c}\text { Instituição } \\
\text { C }\end{array}$ & 2008 & Vila Velha & Estatuto social & Judô & 1 \\
\hline $\begin{array}{c}\text { Instituição } \\
\text { D }\end{array}$ & 1995 & Vitória & $\begin{array}{c}\text { Tipificação Nacional } \\
\text { de Serviços } \\
\text { Socioassistenciais } \\
\qquad(2014) ; \\
\text { Orientações técnicas } \\
\text { sobre o serviço de } \\
\text { convivência e } \\
\text { fortalecimento de } \\
\text { vínculos para crianças } \\
\text { e adolescentes de } 6 \text { a } \\
15 \text { anos (2010). }\end{array}$ & $\begin{array}{l}\text { Música, dança, artes } \\
\text { circenses, capoeira, } \\
\text { jogos brinquedos e } \\
\text { brincadeiras (JBB), } \\
\text { artes, esportes. }\end{array}$ & 14 \\
\hline
\end{tabular}

Fonte: As instituições (2019).

Ressaltamos que os documentos analisados neste estudo foram: Estatutos (instituições A, B e C) e a Tipificação Nacional para Serviços Socioassistenciais, combinado às Orientações Técnicas sobre o Serviço de Convivência e Fortalecimento de Vínculos para crianças e adolescentes de 6 a 15 anos (instituição D). A instituição D segue a um conjunto de documentos nacionais, tanto para atendimento quanto para a contratação de recursos humanos, são eles: Leis Orgânicas, Cadernos de Orientações, Orientações Técnicas, Tipificação de Serviços Socioassistenciais e Norma Operacional Básica. Vale salientar que a instituição D iniciou suas atividades como projeto social no ano de 1995 e, posteriormente, se tornou parte de um Serviço de Convivência e Fortalecimento de Vínculos da Atenção Básica, do SUAS.

Empregamos uma análise descritivo-interpretativa nos documentos das instituições investigadas, que, de acordo com Thomas e Nelson (2007), permite a compreensão no sentido de avaliar o mérito de alguma prática, programa, movimento ou evento. Nesse processo, focalizamos os objetivos e os modos de operar com as atividades físicas e esportivas presentes nesses documentos, que foram examinados criticamente em diálogo com a literatura acadêmica. 


\section{O Termo Currículo e as suas Aproximações com os Projetos Sociais}

Embora reconheçamos as diferenças entre a educação formal (escolarizada) e a não-formal (projetos sociais, dentre outros espaços educacionais informais), compreendemos que qualquer ação educativa deliberada, intencional e planejada necessita de formulações prescritas que sistematizem as suas intenções. Essas sistematizações, sejam elas voltadas as ações de pedagogia formal ou da pedagogia social, aqui denominamos de currículos prescritos.

O termo currículo está carregado de diversos sentidos, que, por vezes, dificulta o estabelecimento de um significado que seja capaz de abranger todas as suas funções e compreensões. Muito disso se deve ao fato dessa palavra ser empregada em situações variadas no que tange o aspecto organizacional do ensino. Segundo Sacristán (1998, p.103), “[...] o conceito currículo adota significados diversos, porquê, além de ser suscetível a enfoques paradigmáticos diferentes, é utilizado para processos ou fases distintas do desenvolvimento curricular".

Lopes e Macedo (2011) trazem à tona este mesmo entendimento quanto à multiplicidade dos significados para o termo currículo e afirmam, ainda, que cada novo conceito não é apenas uma forma diferente de descrever o objeto, mas de pensá-lo de maneira mais ampla, como acordos sobre os seus sentidos locais e identitários, histórica e socialmente situados.

Uma compreensão reducionista, que se tornou senso comum sobre o currículo, está atrelada à "grade curricular”, ou seja, àquilo que é ofertado em termos disciplinares ao longo de um determinado período de tempo. No entanto, a organização prescrita das disciplinas curriculares é uma de suas funções do currículo, não sinônimo de sua abrangência e concretude. 
A constituição de um currículo prescrito parte de uma concepção de ensino, de ser humano, de sociedade, dos objetivos almejados, perfil do egresso, apresenta os procedimentos metodológicos, distribuição dos conteúdos no tempo, formas de avaliar, dentre outras dimensões. Essas características estão vinculadas a situações de ensino e de aprendizagem em diferentes contextos, seja na educação formal ou nos projetos sociais, no entanto, documentalmente, se apresentam em formatos específicos.

Discutir a pertinência dos currículos em projetos sociais sinaliza para a compreensão de que nesses espaços ocorrem movimentos de ensino e de aprendizagem, e que esses movimentos demandam sistematizações para que os objetivos sejam alcançados de forma qualificada. Autores que discutem os processos educacionais no campo da pedagogia social (MULLER, 2017; CARDOZO, 2017), incluindo os projetos sociais, rechaçam a terminologia educação não-formal para designar as ações pedagógicas desenvolvidas nesses contextos. Para esses autores, tal terminologia pressupõe falta de planejamento, de metodologias e de organização nas ações educacionais desenvolvidas em contextos extraescolares. Para eles, há uma formalidade nessas ações, porém, distintas daquelas empregadas na escola.

Com base em Sacristán (2013), compreendemos que não há neutralidade no currículo. O que, como, para que, para quem e quando ensinar são questões que definem as opções curriculares, dentre várias alternativas possíveis. Dessa forma, seja em ambiente escolar ou fora dele, o currículo constitui-se, para além da função de orientação institucional, como um elemento de regulação social, pois a sua efetivação pressupõe a formação dos indivíduos em uma determinada direção moral, ética e social. Por exemplo, têm instituições que, em suas práticas curriculares, preconizam a formação do indivíduo para o mundo do trabalho, já outras estão mais preocupadas em formar o cidadão. 
Cada projeto tem a sua gênese motivada por questões específicas e circunstanciais, próprias de seus contextos de inserção. No entanto, os projetos sociais parecem comungar de um mesmo princípio geral: ampliar as oportunidades em prol da equidade social, para que menos pessoas se encontrem em situação de vulnerabilidade social. Devido a essa diversidade, os documentos que orientam as práticas nos projetos sociais (currículos prescritos) não possuem um único formato e/ou padrão. Por vezes, eles estão sistematizados em forma de estatuto, de regimento, de históricos ou de documentos institucionais.

Nesse sentido, cada projeto social ou até mesmo unidades do mesmo projeto, situados em localidades diferentes, apresentam orientações prescritas próprias. Diferentemente dos currículos escolares, que possuem estruturas textuais mais universais e estáveis [concepção de sociedade, de homem, de educação, objetivos, metodologia, conteúdos, formas de avaliar, dentre outros aspectos], os documentos prescritos dos projetos sociais, em sua maioria, são mais restritos e não apresentam os desdobramentos detalhados de suas intenções pedagógicas. Em muitos casos, essas intenções estão misturadas com os aspectos administrativos e gerencias do projeto.

Apesar da dimensão prescrita dos currículos, compreendemos que “[...] toda proposta de texto é traduzida pelos leitores. Quando ela é interpretada, pode ser enriquecida e inclusive subvertida pelos leitores" (SACRISTÁN, 2013, p. 27). É consensual a importância de propostas curriculares prescritas bem fundamentadas e estruturadas, no entanto, é imprescindível à atenção para os movimentos de interpretação e de práticas curriculares, para que sejam possíveis compreensões mais próximas do contexto de ensino e de aprendizagem em questão.

Sobre as formas do currículo, Lopes e Macedo (2011) indicam três níveis indissociáveis: formal, oculto e vivido. O formal diz respeito às dimensões institucional 
e prescrita; o oculto às ideologias subjacentes às escolhas na construção do currículo; e o vivido diz respeito às ações diárias, que dão materialidade ao currículo praticado. Para que haja coerência nas práticas educacionais, a articulação dessas formas curriculares é necessária e a potência não está na sobreposição de uma forma pela outra, mas na compreensão e interlocução de todas elas no processo de ensino e de aprendizagem.

Embora reconheçamos a importância e as interconexões de todas as dimensões curriculares, para o escopo deste estudo, focalizaremos a dimensão prescrita dos documentos que orientam as práticas pedagógicas em projetos sociais da Região da Grande Vitória/ES. Sem a intenção de negar ou de hierarquizar as outras dimensões curriculares, compreendemos que as orientações prescritas são fundamentais para as práticas pedagógicas nas instituições educacionais, escolares ou não, pois constituem-se como a face concreta e objetiva das intenções institucionais.

\section{Das Intenções às Prescrições: Análises dos Documentos Orientadores de Projetos}

\section{Sociais}

Compreendendo o currículo como prescrição organizacional e institucional das práticas educativas e socioeducativas, é possível afirmar que os projetos sociais e serviços socioassistenciais também possuem documentos orientadores que assumem a características de currículos prescritos. No entanto, a organização documental que apresenta os tipos de oficinas e conteúdos desenvolvidos varia conforme o grupo gestor de cada instituição, assim como o tipo de relações construídas com os profissionais responsáveis pelas práticas socioeducativas.

A partir da leitura e da apreciação dos três estatutos, da Tipificação Nacional de Serviços Socioassistenciais e do documento de Orientações Técnicas sobre o Serviço de Convivência e Fortalecimento de Vínculos para crianças e adolescentes de 6 a 15 anos, 
apresentaremos reflexões com base em doiseixos de análise, relacionando-as às questões norteadoras deste estudo. Para tanto, serão apresentados separadamente para melhor fluidez textual. Iniciaremos com o título da análise, apresentação da temática, quadro para exposição da categoria, seguido por texto reflexivo.

\section{As Ações Socioeducativas nos Documentos Prescritos: Análise dos Objetivos}

Ao considerarmos o currículo como documento e instrumento regulador das práticas institucionais, percebemos que em projetos sociais ocorrem também movimentos de sistematização das ações socioeducativas. A aproximação documental é mais visível a partir da concepção de ensino, que está disposta nas finalidades/objetivos institucionais de todos os documentos aqui analisados, pois demarcam o que pretendem com o atendimento socioeducativo e o tipo de sociedade para qual esperam contribuir.

Partindo do princípio de que as instituições que cederam os documentos analisados nesta pesquisa não possuem um documento denominado currículo, nos atemos às possíveis pistas que indiquem algum tipo de construção curricular/sistematização para atendimentos socioeducativos. Por meio da leitura do material, elaboramos o Quadro 2, onde sintetizamos os objetivos institucionais, que nos oferecem indícios acerca do que cada instituição pretende alcançar com a oferta de suas atividades específicas.

\section{Quadro 2: Objetivos institucionais declarados pelas instituições}

\begin{tabular}{|c|c|}
\hline \multicolumn{2}{|r|}{ OBJETIVOS INSTITUCIONAIS } \\
\hline $\begin{array}{c}\text { Instituição } \\
\text { A }\end{array}$ & $\begin{array}{l}\text { Art. } 3^{\circ} \text { - [...] busca de uma sociedade primada pela democracia participativa, pela justiça, pela } \\
\text { liberdade, igualdade de condições, segurança e, direito à vida, pelo respeito às diversidades } \\
\text { culturais e religiosas e numa inequívoca posição em favor dos seres humanos tem por } \\
\text { objetivos e finalidades: I. Acolher, promover e orientar crianças e adolescentes menos } \\
\text { favorecidas socioeconomicamente, contribuindo para o seu desenvolvimento físico, humano, } \\
\text { moral e ético; II. Atuar em colaboração com os familiares das crianças e adolescentes e com } \\
\text { as comunidades de origem; III. O pleno desenvolvimento da criança e adolescente e seu } \\
\text { preparo para o exercício da cidadania. Valores espirituais, éticos e morais. }\end{array}$ \\
\hline & $\begin{array}{l}\text { I - Promover o resgate, a preservação e a pesquisa histórica, social e econômica dos vários } \\
\text { aspectos da capoeira e de quaisquer outras manifestações da cultura afro-brasileira no país } \\
\text { e/ou no exterior; II - Promover a cultura e a defesa e conservação do patrimônio histórico e }\end{array}$ \\
\hline
\end{tabular}




\begin{tabular}{|c|c|}
\hline $\begin{array}{c}\text { Instituição } \\
\text { B }\end{array}$ & 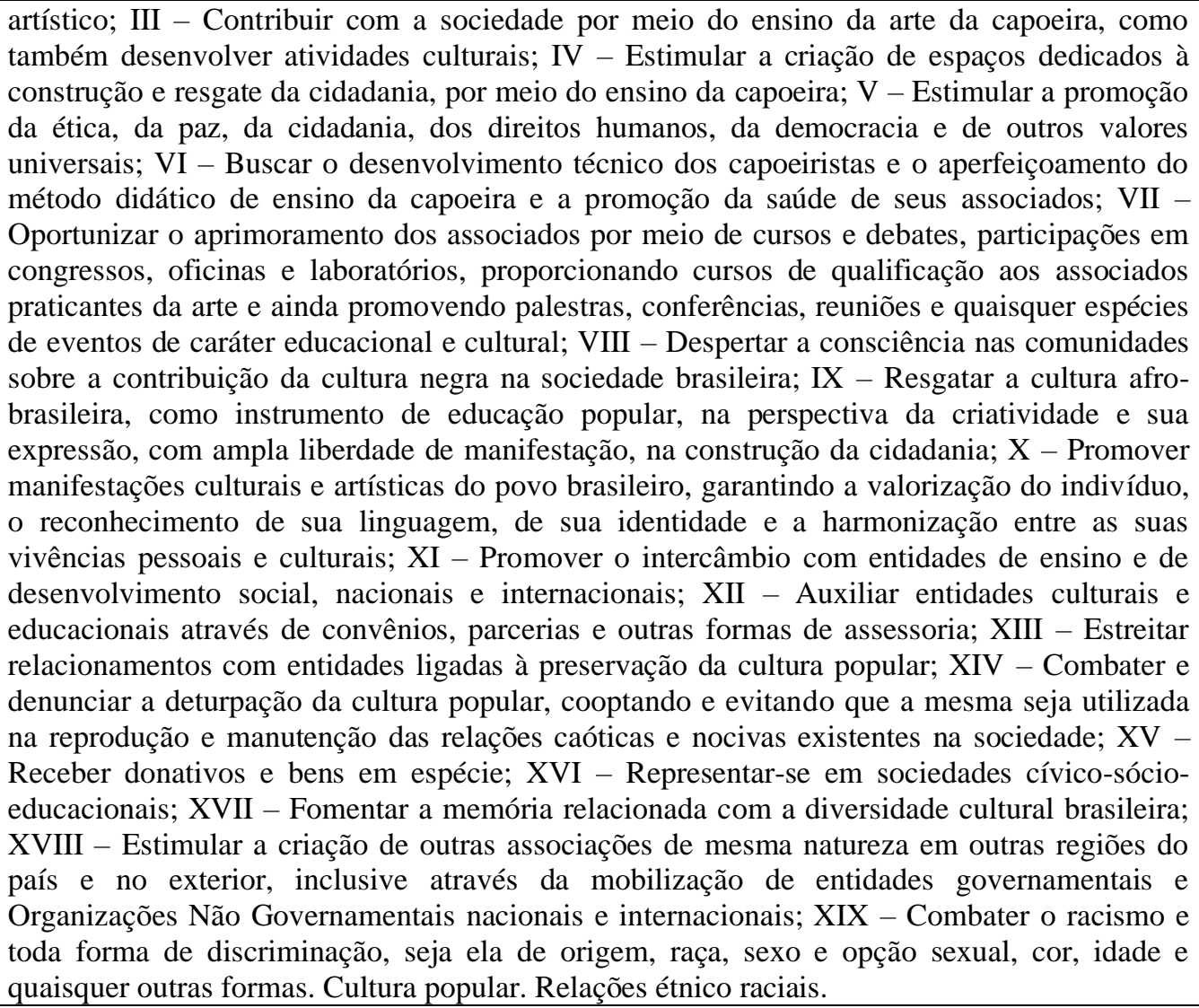 \\
\hline $\begin{array}{c}\text { Instituição } \\
\text { C }\end{array}$ & $\begin{array}{l}\text { a) Desenvolver, promover e difundir a prática do judô e de outros esportes de acordo com a } \\
\text { determinação de seus associados; b) Desenvolver, promover e difundir todas as formas de } \\
\text { cultura, independente da região, nacionalidade e religião; c) Desenvolver, promover e difundir } \\
\text { o lazer em todas as suas formas; d) realizar atividades, projetos e programas nas áreas de meio } \\
\text { ambiente, educação, artes, cultura e desenvolvimento social; e) representar interesses } \\
\text { coletivos dos associados perante o poder público e instituições em geral, no que diz respeito a } \\
\text { sua missão e objetivos; f) Contribuir para o fortalecimento de mecanismos institucionais de } \\
\text { proteção e conservação do meio ambiente; g) Participar e promover programas de educação, } \\
\text { difusão de conhecimento e de conscientização de cuidados com o meio ambiente; h) Criar, } \\
\text { produzir e disseminar conhecimentos especializados, que tenham na ecologia seu tema } \\
\text { principal; i) Assessorar, prestar serviços, orientar e participar em programas, projetos e outras } \\
\text { formas de ação técnica, coletiva, pública ou privada, que promovam o meio ambiente; j) } \\
\text { colaborar com organizações congêneres e com o poder público em iniciativas afins com sua } \\
\text { missão e objetivos Ecologia. Preservação ambiental. }\end{array}$ \\
\hline $\begin{array}{c}\text { Instituição } \\
\text { D }\end{array}$ & $\begin{array}{l}\text { Tem por foco a constituição de espaço de convivência, formação para a participação e } \\
\text { cidadania, desenvolvimento do protagonismo e da autonomia das crianças e adolescentes, a } \\
\text { partir dos interesses, demandas e potencialidades dessa faixa etária. As intervenções devem } \\
\text { ser pautadas em experiências lúdicas, culturais e esportivas como formas de expressão, } \\
\text { interação, aprendizagem, sociabilidade e proteção social. Inclui crianças e adolescentes com } \\
\text { deficiência, retirados do trabalho infantil ou submetidos a outras violações, cujas atividades } \\
\text { contribuem para re-significar vivências de isolamento e de violação de direitos, bem como } \\
\text { propiciar experiências favorecedoras do desenvolvimento de sociabilidades e na prevenção } \\
\text { de situações de risco social, protagonismo e autonomia dos sujeitos, combate ao trabalho } \\
\text { infantil e violação de direitos. }\end{array}$ \\
\hline
\end{tabular}

Fonte: AAOCA (2017); ACDASCC (2018); IVOS (2017), BRASIL (2010); BRASIL (2014).

Depreendemos, do Quadro 2, que há preocupações diversificadas entre as

instituições analisadas, tais como: valores espirituais, éticos e morais (Instituição A);

cultura popular e relações étnico raciais (Instituição B); ecologia e preservação 
ambiental (Instituição C); e protagonismo e autonomia dos sujeitos, combate ao trabalho infantil e violação de direitos (Instituição D).

Observamos que a Instituição A almeja construir, junto aos seus participantes, comportamentos virtuosos que gerem ações perante ao outro e a si próprio. Em outros termos, busca fomentar posturas eticamente orientadas no sentido da moralidade. Concordamos com Nalini (2009), que o conceito de ética está intimamente ligado ao de moral, e que, toda suposta crise moral em nossa sociedade toma como referência para sua identificação valores básicos de orientação de comportamentos, atribuindo à ética a função de "remédio" para os males causados pela ausência de comportamentos, posturas, ações e posicionamentos moralmente aceitos e partilhados por uma comunidade.

Os valores éticos e morais contidos no documento orientador da Instituição A, embora escritos de forma genérica, não estão isentos das influências religiosas que constituem a própria Instituição. Trata-se de uma organização gerida por uma igreja católica. Portanto, as questões relacionadas a promoção da cidadania ancoram-se em um conjunto de condutas e normas assentadas na compreensão da realidade pela ótica daquilo que acreditam ser "correto", do ponto de vista de suas crenças (PEREIRA, 2005).

A Instituição B evidencia em seus objetivos institucionais estar fortemente dedicada à valorização da cultura popular e ao combate ao racismo. Para tanto, assume a capoeira como manifestação artística e cultural, que dialoga com construção identitária do povo brasileiro. Consideramos fundamental que as questões étnico-raciais ocupem lugar nos currículos e nas discussões pedagógicas, seja na escola ou em projetos sociais.

A capoeira é uma valiosa expressão da cultura afro-brasileira que contribui na construção da identidade nacional. De acordo com Sodré (1996, p. 68), “[...] a capoeira, 
é um jogo com identidade cultural, ou seja, é uma atividade corporal que remete a uma história e seus desdobramentos na atividade concreta dos sujeitos”. É importante ponderar que a uma "identidade nacional" pretendida é resultante de uma "costura" entre diferenças culturais abrigadas em um mesmo país, bem como é permeada por tensões próprias da dinâmica social e das rápidas transformações em que as sociedades estão sujeitas, tendo em vista os processos de globalização (HALL, 2005).

Em relação ao exposto, a Instituição B é bem incisiva ao afirmar que deseja promover manifestações culturais consideradas "do povo brasileiro", valorizando a identidade. Assim como, é bastante enfática ao defender que o trabalho pedagógico com a cultura popular no Projeto visa "combater e denunciar" possíveis "deturpações" e a "reprodução de relações caóticas e nocivas" na sociedade. Há, portanto, uma evidente preocupação de favorecer ao seu público, apropriações teóricas e práticas em uma perspectiva crítica das atividades desenvolvidas.

A Instituição $C$ assume a ecologia e a preservação ambiental como mote principal de suas pretensões formativas. Os objetivos institucionais descritos no Quadro 2 denotam que a educação promovida no interior do Projeto alinha-se com as discussões que problematizam a questão ambiental. Conforme constatado por Costa; Silva e Votre (2011) vêm aumentando o número de organizações governamentais e nãogovernamentais que se dedicam a propor alternativas para o uso racional dos recursos ambientais a partir do "movimento educacional em prol do desenvolvimento sustentável". Nesse caso, tem sido relevante a participação de instituições sociais que trabalham com o esporte e com a Educação Física nessa perspectiva.

Os autores indicam ser necessário, mais do que apontar a ausência de consciência ecológica por parte da sociedade, propor uma “[...] agenda de ações educativas em que os esportistas se transformem em agentes de monitoração, denúncia 
de ações destrutivas e, sobretudo, mentores de melhoria de alguns aspectos críticos da realidade ambiental" (COSTA; SILVA; VOTRE, 2011, p. 10).

Por sua vez, a Instituição D mira as suas ações no fomento ao protagonismo e a autonomia dos sujeitos, aliado ao combate ao trabalho infantil. Tem como documento de orientação principal a "Tipificação Nacional para Serviços Socioassistenciais" e as "Orientações sobre o Serviço de Convivência e Fortalecimento de Vínculos para crianças e adolescentes de 6 a 15 anos", visando estabelecer orientações para os projetos e serviços socioassistenciais referenciados no SUAS.

Por ser uma instituição ligada ao SUAS, entendemos como coerente esse foco na emancipação e proteção do indivíduo. Nascimento e outros (2019, p. 24-25) asseguram que o SCFV tem o intuito:

[...] de estimular a ampliação e troca de culturas e vivencias, desenvolvendo o sentimento de pertença no meio comunitário. Além de possuir um caráter preventivo e proativo, se relaciona na defesa e afirmação de direitos e no desenvolvimento de capacidades e potencialidades dos usuários, garantindo as seguranças de acolhida, de convívio familiar e comunitário, impulsionando o desenvolvimento da autonomia dos usuários.

Ao analisarmos os objetivos institucionais transcritos no Quadro 2, é possível observar que as Instituições A e D empreendem esforços centrados nos sujeitos, de forma mais individualizadas, e que, as Instituições $\mathrm{B}$ e $\mathrm{C}$, ao contrário, buscam desenvolver ações de caráter mais coletivo/comunitário. Em comum, podemos afirmar que há uma preocupação direcionada a construção da cidadania, entendida como a adoção de posturas, comportamentos e hábitos importantes para a convivência em sociedade.

Portanto, os projetos sociais selecionados nesta pesquisa enxergam a necessidade de construir com o público por eles atendidos, seja priorizando os aspectos mais individuais ou os mais coletivos, relações consideradas harmônicas entre 
diferentes sujeitos e desses sujeitos com a coletividade. Sobre as relações entre as dimensões individuais e as coletivas nos projetos socioeducativos, Souza (2016, p. 130) afirma que as ações estão "[...] relacionadas mais diretamente com o âmbito individual, pois gera resultados ou efeitos na vida privada dos sujeitos. Mas esses resultados podem resplandecer em outros âmbitos".

Ribeiro (2008) nos alerta que o termo cidadania tem sido empregado de forma excessiva e indiscriminada em discursos políticos, em estatutos sociais, em campanhas publicitárias de empresas privadas, entre outras. Em sua avaliação, expõe o termo a um esvaziamento de sentido. Acrescenta ainda que o emprego corrente do conceito "[...] decorra do seu valor social e não do reconhecimento do significado que esta carrega. Ações sociais para o desenvolvimento da cidadania comumente são bem-vistas, mesmo quando não se tem definido qual cidadania almeja” (RIBEIRO, 2008, p. 112).

Verificamos que essa leitura de Ribeiro (2008) coincide com as formas diversificadas e difusas com que o termo cidadania foi empregado nos objetivos institucionais: “[...] preparo para o exercício da cidadania” (Instituição A); “[...] resgate da cidadania, por meio do ensino da capoeira", "Estimular a promoção da ética, da paz, da cidadania, [...]", Resgatar a cultura afro-brasileira, como instrumento de educação popular, [...] na construção da cidadania” (Instituição B); “[...] formação para a participação e cidadania [...]" (Instituição D).

Diante dessa indefinição sobre a perspectiva de cidadania almejada pelos projetos sociais, sinalizamos que o desenvolvimento da autonomia e do protagonismo dos sujeitos, preconizada, sobretudo, pelo Projeto D, está associada à cidadania reclamada. Para Stoer; Magalhães e Rodrigues (2004), nesse modelo de cidadania, os indivíduos assumem as ações e os discursos sobre si próprios, eles não esperam apenas que o poder público ou grupos externos estabeleçam as suas prioridades. Na cidadania 
reclamada, interessa aos sujeitos optar pelos modos de se educar, de viver, de se relacionar, a partir de questões associadas à identidade coletiva, em interação com as agências educativas.

Em síntese, não há uma definição clara nos documentos que indique qual a concepção de cidadania essas instituições adotam. Os três Estatutos, a "Tipificação Nacional de Serviço Socioassistencial" e as "Orientações Técnicas sobre os Serviços de Convivência e Fortalecimento de Vínculos para crianças e adolescentes de 6 a 15 anos" aqui analisados expressam a intenção de melhorias para seus participantes quanto ao desenvolvimento de consciência cidadã, diminuição das vulnerabilidades sociais e ganhos culturais a partir das atividades físicas, esportivas, artísticas e culturais que ofertam.

\section{Dos Objetivos aos Modos de Operar com as Atividades Físicas e Esportivas nos}

\section{Projetos Sociais}

Os estatutos sociais analisados das Instituições A, B, C e D têm como objetivo regular o funcionamento de instituições e o nível de participação de seus associados. As quatro instituições, de forma geral, apresentam as práticas corporais de suas oficinas (segundo os documentos) como instrumentos de manutenção, reforço e viabilizador do alcance das finalidades às quais se propõem. O Quadro 3, a seguir, expõe cada uma delas:

\section{Quadro 3: Atividades físicas e esportivas oferecidas pelas Instituições}

\begin{tabular}{|c|c|}
\hline & Atividades físicas e esportivas nos documentos analisados \\
\hline $\begin{array}{c}\text { Instituição } \\
\text { A }\end{array}$ & $\begin{array}{l}\text { Art. } 4^{\circ} \text { - Para atender as finalidades a que se propõe, a "instituição A" } \\
\text { desenvolverá as seguintes atividades: I. Oficinas de cidadania, música, teatro, dança, } \\
\text { pintura, informática, idiomas, trabalhos artesanais, esporte e de literatura; [...] }\end{array}$ \\
\hline $\begin{array}{c}\text { Instituição } \\
\text { B }\end{array}$ & $\begin{array}{l}\text { Art. } 1^{\circ} \text { - [...] é uma associação, com personalidade jurídica própria, distinta dos seus } \\
\text { associados, de direito privado, de representação comunitária, de caráter social, } \\
\text { cultural, esportivo e filantrópico, para a difusão e a prática da capoeira [...]. } \\
\text { Parágrafo único. Os trabalhos desenvolvidos com capoeira pela "instituição B" } \\
\text { estarão vinculados ao Grupo de Capoeira Beribazu e obedecerão ao seu Estatuto e ao } \\
\text { seu Código de Ética e Disciplina. Outros grupos de capoeira que quiserem participar }\end{array}$ \\
\hline
\end{tabular}




\begin{tabular}{|c|c|}
\hline & da Associação terão que ser aprovados em assembleia. \\
\hline $\begin{array}{c}\text { Instituição } \\
\text { C }\end{array}$ & $\begin{array}{l}\text { Art. } 2^{\circ} \text { - "A instituição C" é uma associação de caráter esportivo, sociocultural. } \\
{[\text { sic][...]. }} \\
\text { Art. } 3^{\circ} \text { - Destina-se ainda, "a instituição C", a manter o judô como seu principal e } \\
\text { básico esporte, participando ou se fazendo representar nos eventos esportivos a nível } \\
\text { municipal, estadual e nacional. } \\
\text { PARÁGRAFO ÚNICO - "A instituição C" reconhece como entidades máximas } \\
\text { representativas do Judô no Espírito Santo e no Brasil, a Federação Espiritossantense } \\
\text { de Judô (FEJ) e a Confederação Brasileira de Judô (CBJ) respectivamente, e } \\
\text { consequentemente se filiará a aquela federação, que é a representante legal da CBJ } \\
\text { neste Estado. } \\
\text { Art. 5o - Compromete-se "a instituição C", dentro dos princípios que regem seus } \\
\text { objetivos: incentivar, organizar e promover eventos nas áreas de esporte, } \\
\text { cultura e lazer, dentro ou fora de sua sede respeitando os regulamentos de FEJ } \\
\text { e CBJ. } \\
\text { Art. } 6^{\circ} \text { - "A instituição C", reconhece e acata as normas técnicas, disciplinares e } \\
\text { regulamentos da Federação Espiritossantense de Judô (FEJ) e da Confederação } \\
\text { Brasileira de Judô (CBJ), bem como de qualquer outra entidade representativa de } \\
\text { outra modalidade esportiva a qual vier se filiar. }\end{array}$ \\
\hline $\begin{array}{c}\text { Instituição } \\
\text { D }\end{array}$ & $\begin{array}{l}\text { Trabalhando o corpo e a mente: Jogos matemáticos; Jogos esportivos; Jogos } \\
\text { recreativos; Jogos com palavras. Oficinas: 1. Artes plásticas (desenho, pintura e } \\
\text { outras formas) 2. Teatro/dramatização; 3. Dança (regionais, modernas, clássicas); } 4 . \\
\text { Música (coral, instrumentos diversos); 5. Contação de histórias; 6. Cantinho de } \\
\text { leitura. } \\
\text { O jogo oferece à criança e ao adolescente uma relação com o limite, com regras, com } \\
\text { o certo e o errado, e com a forma como devem lidar com as leis estabelecidas por eles } \\
\text { ou por um determinado grupo. É importante que as regras e os limites sejam } \\
\text { discutidos com todos os envolvidos nas atividades. O jogo pode representar para o } \\
\text { indivíduo uma forma de inclusão no grupo social pela qual ele aprende a ouvir e a } \\
\text { considerar o ponto de vista do outro, a ganhar, a perder e a respeitar regras na } \\
\text { construção comum da vivência em grupo. } \\
\text { É interessante que o Orientador Social e/ou o Facilitador de Oficinas estimule as } \\
\text { crianças e os adolescentes a criarem coreografias, improvisarem ritmos diferentes e } \\
\text { sequências de movimento. As danças regionais, modernas e clássicas podem (e } \\
\text { devem) ser usadas como meios de crítica social, para o questionamento de valores } \\
\text { preestabelecidos, padrões repetitivos e modismos, como as coreografias com fortes } \\
\text { apelos sexuais que aparecem incessantemente em programas de TV. }\end{array}$ \\
\hline
\end{tabular}

Fonte: AAOCA (2017); ACDASCC (2018); IVOS (2017), BRASIL (2010); BRASIL (2014).

$\mathrm{Na}$ Instituição $\mathrm{A}$, as oficinas são apresentadas como meio para atingir os

objetivos socioeducativos. Não é especificado quais são as modalidades esportivas ofertadas e o modo como elas são desenvolvidas no Projeto, o documento analisado cita apenas a oferta de esportes, de maneira geral, e a dança como manifestação da cultura corporal. Prevalece, nesse caso, representações positivas e mecânicas sobre a prática esportiva, em que ela, por si só, é capaz de promover valores éticos e morais desejados, desassociada de qualquer intencionalidade pedagógica que esteja subjacente a essa prática (DaCOSTA, 2009). 
A Instituição B lida com a prática da capoeira e em seu estatuto todas as finalidades perpassam as práticas culturais desta modalidade, apontam ainda que a instituição acata ao estatuto do grupo de capoeira Beribazu e não explicitam a faixa etária atendida, sem discorrer sobre como a Capoeira e o Estatuto do Grupo Beribazu contribuem para a efetivação dos objetivos institucionais traçados. ${ }^{6}$

A leitura do Estatuto do Grupo Beribazu ${ }^{7}$ nos permite identificar divergências entre o que almeja o projeto social gerido pela Instituição B e a finalidade do referido Grupo. O Quadro 2 sinaliza que o objetivo do Projeto busca o resgate, a reflexão, a promoção e a valorização da cultura popular como um todo, da construção da identidade nacional mediada pela cultura popular e pela capoeira em sentido amplo, do combate ao racismo, dos desafios relativos as questões étnico-raciais em nosso país, entre outros. Em direção oposta, o estatuto afirma:

Art. $4^{\circ}$ - O Grupo Beribazu, através dos seus filiados individualmente, ou dos seus núcleos de capoeira, tem por finalidades:

a) implementar a sua própria história, mantendo a coerência de suas concepções, valores, princípios, processos e preceitos;

$[\ldots]$

e) postular a adoção de medidas legais de resgate seletivo das tradições populares, de proteção e de preservação da capoeira assim como dos bens culturais brasileiros.

§ Único - O Grupo não tem finalidades religiosas, comerciais, filantrópicas, político-partidárias ou étnico-raciais (ESTATUTO GRUPO BERIBAZU, 1999, grifo nosso).

Como demonstrado, o Estatuto do Grupo de Capoeira tomado como referência para as ações da Instituição B caminham na direção de promover as suas próprias convicções acerca da capoeira e do seu entendimento de cultura, ou seja, de maneira restritiva e não ampliada como pretende a Instituição B. Cabe ressaltar que é legítima a opção do Grupo de Capoeira em não adentrar nas questões étnico-raciais, em fomentar

\footnotetext{
${ }^{6}$ Vide Quadro 2.

7 Disponível em: http://www.capoeiraberibazu.com/uploads/8/0/0/4/80048086/estatuto_beribazu.pdf. Acesso em: 18 jun. 2020.
} 
um resgate seletivo das tradições populares e de focar na implementação da sua própria história, pois se constitui como uma organização voltada para o atendimento das suas próprias contingências. Diferentemente do Projeto, que perspectiva efetivar um trabalho mais ampliado que leva em conta as questões étnico-raciais, de combate ao racismo e de valorização da cultura popular brasileira. Além dessas questões divergentes, notamos que o Estatuto não contempla qualquer menção as questões relacionadas ao "como fazer”, ou seja, não indica por quais caminhos essas práticas se materializam.

A Instituição C, embora enfatize a questão ambiental como objetivo do Projeto, seu documento apresenta um viés tecnicista da prática do judô, ressaltando, inclusive, o papel decisivo que as federações nacionais e estadual de Judô têm na concepção das atividades. Esse caráter técnico-esportivo é reforçado pela afirmação de que, caso o Projeto agregue outra modalidade, essa também será guiada pelas normas da respectiva federação esportiva a qual está vinculada.

Assim como a Instituição B, a Instituição C busca respaldo em estatuto de outras entidades, nesse caso, no da Confederação Brasileira de Judô (CBJ). Esse estatuto ${ }^{8}$ também não discute as questões ecológicas e ambientais. Se restringe a normatizar a prática padronizada do Judô no território nacional e lançar diretrizes para a organização de competições esportivas da modalidade. $\mathrm{O}$ estatuto da CBJ não oferece bases para se pensar a prática do Judô articulada com a temática da sustentabilidade ambiental.

Na Instituição D, a tipificação nacional para serviços socioassistenciais não especifica as modalidades de oficinas a serem desenvolvidas nos atendimentos socioeducativos. As orientações são gerais, fazendo com que as atividades físicas, esportivas e artísticas sejam utilizadas como ferramentas para atingir os objetivos designados pela Secretaria de Assistência Social desde o nível federal ao municipal.

\footnotetext{
${ }^{8}$ Disponível em: https://cbj.com.br/normas_e_regulamentos. Acesso em: 18 jun. 2020.
} 
Percebemos que há uma preocupação com a organização operacional dos SCFV de maneira geral, como: divisão do atendimento por faixa etária (6 a 15 anos de idade); o atendimento máximo de 20 educandos por turma; o estabelecimento de dois eixos norteadores dos serviços (convivência social e participação); viabilização de espaços adequados para as atividades; necessidade de planejamento participativo e intersetorialidade; capacitação das equipes em serviço; objetivos a serem alcançados.

Há indicações gerais de atividades e oficinas a serem ofertadas e suas possíveis contribuições para os $\mathrm{SCFV}$ e, no que diz respeito as atividades de caráter físico e esportivo trazem como exemplo a dança e os jogos. As Orientações Técnicas que regem a Instituição D contextualizam o que entendem por jogos e afirmam que contribuem para a compreensão de mundo, resolução de conflitos cotidianos e demais colaborações. A relação que estabelecem com as regras a partir dos jogos se mostra ainda mais potente quando mencionada a necessidade de construção de pactos de convivência para criação e fortalecimento dos grupos, uma forma de praticar as regras que acordaram em conjunto. Utilizam como exemplos: jogos matemáticos; esportivos; recreativos e com palavras.

O foco do trabalho com os jogos reside na construção da autonomia dos sujeitos. O modo como as regras devem ser pautadas na relação dos educadores com as crianças e adolescentes nos remete as ideias de Piaget (1994) acerca da construção do desenvolvimento moral, que reúne três estágios: a anomia, a heteronomia e a autonomia. Para Seabra e Rossetti (2016, p. 137), o alcance do estágio definido por Piaget (1994) como autonomia combina a presença de posicionamentos que refletem cooperação e respeito mútuo no julgamento das ações; com o desenvolvimento da capacidade de se colocar no lugar do outro e de perceber a intencionalidade das ações, demonstrando gradativa elevação da capacidade de descentração. 
Para o trabalho com a dança, apresenta diversas possibilidades: a diferença entre gêneros; domínio corporal e ritmicidade; a diversidade cultural e os variados estilos; a autoestima e o desenvolvimento de novas capacidades. Essas questões se alinham a perspectiva de fomentar o protagonismo e a autonomia, na medida em que os participantes são instados a "[...] criarem coreografias, improvisarem ritmos diferentes e sequências de movimentos" (BRASIL, 2010, p. 114). Esse processo desejado pela Instituição D (Quadro 2) e construído de modo crítico, em que os projetos sociais promovem uma educação com base na formação de "autores-cidadãos" e o protagonismo vivido por meio das danças oferece às crianças e aos adolescentes a oportunidade de se constituírem como "autores de si próprios" (MAGRO, 2002).

Embora percebamos a ausência da apresentação de outras modalidades físicas e esportivas como as desenvolvidas na instituição D (capoeira, jogos e brincadeiras, esportes), compreendemos que independentemente da modalidade, os princípios socioeducativos são comuns, respeitando o número de participantes, os eixos estruturantes e objetivos do atendimento, linguagem apropriada para as diferentes idades, indicação de espaços e materiais adequados.

Verificamos, de maneira geral, nos documentos das quatro instituições analisados, que há um distanciamento entre as intenções presentes nos seus objetivos e os percursos delineados para alcançá-los por meio das atividades físicas e esportivas. A Instituição A apresenta possibilidades para a oferta de oficinas, mas não os modos de operar. A Instituição B associa as práticas do projeto ao estatuto do Grupo de Capoeira Beribazu. A Instituição C, por sua vez, indica a vinculação de suas atividades com o estatuto da federação estadual de judô do Espírito Santo e da CBJ. Por fim, a Instituição D expõe algumas estratégias para o desenvolvimento das atividades com os jogos e as danças. 
Há um hiato entre as intenções prescritas nos objetivos e o desdobramento das atividades físicas e esportivas no interior dos documentos, sobretudo, em três dos Projetos analisados. Eles anunciam que pretendem desenvolver valores espirituais, éticos e morais (Instituição A); a cultura popular e as relações étnico-raciais (Instituição B); e a ecologia e preservação ambiental (Instituição C). Entretanto, os documentos analisados desses projetos não apresentam estratégias operacionais para efetivar essas intenções. O desenvolvimento do protagonismo e da autonomia dos sujeitos, assim como o combate ao trabalho infantil e a violação de direitos, objetivos preconizados pela Instituição D, encontram, embora de maneira ampla, desdobramentos operacionais nos documentos que orientam os SCFV.

A dimensão metodológica, que diz respeito às maneiras de efetivar os objetivos propostos, se apresenta como a principal lacuna nos documentos orientadores dos Projetos analisados. O modo como os objetivos serão alcançados é fundamental para a compreensão de qualquer proposta de ação. Conforme defende Kisil (2001), a estruturação de projeto social não deve representar uma camisa de força, limitando a criatividade dos seus executores, porém, também não pode deixar de abordar com consistência o problema em foco e as alternativas escolhidas para enfrentá-lo.

Os documentos prescritos precisam demonstrar uma concatenação lógica entre os elementos que compõem o plano de trabalho do projeto, indicando com clareza os caminhos pelos quais pretende a consecução dos objetivos. Como estão, passam a impressão de que as atividades desenvolvidas, em especial as práticas físicas e esportivas, por si só, são capazes de garantir que as "boas intenções" registradas nos objetivos institucionais se efetivem.

Compreendemos que os documentos orientadores precisam apresentar maior consistência na sistematização e articulação das informações, sobretudo, no que tange às 
questões operacionais. Essa consistência prescritiva contribuirá para superar representações de que as atividades físicas e esportivas são "naturalmente boas" e que, ao praticá-las, os participantes dos projetos sociais irão alcançar os objetivos por eles almejados. O êxito dos projetos está atrelado, em grande medida, à transposição daquilo que está no campo das intenções (objetivos) para o campo das ações (como fazer?).

\section{Considerações Finais}

As ações afirmativas desenvolvidas em projetos de caráter socioeducativo, que buscam promover a equidade social, em um país marcado por profundas desigualdades socioculturais e econômicas, embora não incidam sobre a raiz estrutural do problema, contribuem para diminuir a diferença na distribuição de bens culturais e educativos entre crianças e jovens socialmente vulneráveis. Ao fazermos essa afirmação, não pretendemos reforçar a ideia dos projetos sociais, principalmente àqueles vinculados às atividades física e esportivas, como panaceia para as mazelas sociais. Mas como uma ação complementar, dentre inúmeras iniciativas mais abrangentes, que convergem para a construção de uma sociedade mais justa e igualitária.

No caso específico dos projetos que ofertam atividades físicas e esportivas, além da necessidade de superar representações que circulam no imaginário social, que atribuem valores sociais positivos à essas atividades, independentemente do modo como são praticadas, a organização de currículos prescritos bem estruturados também surge como uma necessidade premente, contribuindo para reduzir, dessa forma, a distância entre os objetivos almejados por esses projetos e as suas formas de consecução.

Compreendemos que o currículo prescrito, por si só, não é a única dimensão concorrente para o êxito das ações pedagógicas nos projetos sociais. Como visto neste estudo, as dimensões ocultas e praticadas do currículo também são imprescindíveis de 
serem consideradas e problematizadas. Contudo, no escopo deste artigo, focalizamos a dimensão prescrita do currículo, compreendendo-a como elemento balizador e orientador das práticas pedagógicas, que deve, em permanente relação dialógica e dialética com as outras dimensões, ser ressignificada e reformulada, expressando, em suas produções textuais, a polifonia dos sujeitos presentes nos cotidianos dos projetos sociais.

Nos documentos dos projetos sociais aqui analisados, apesar das especificidades de cada um deles, verificamos que todos se propõem a desenvolver a cidadania de seus participantes. Embora nobre, tal objetivo, da maneira como aparece nas prescrições documentais, carece de sentidos mais aprofundados. No campo das ciências humanas e sociais o termo cidadania é polissêmico e a falta de uma delimitação mais restrita do modelo almejado, dificulta focalizar as ações naquilo que, de fato, o projeto pretende alcançar.

Quanto às especificidades, os documentos dos projetos analisados centram-se nos sujeitos, com a valorização de questões morais e éticas, assim como no desenvolvimento da autonomia e do protagonismo dos seus participantes. Já os projetos que priorizam focos mais abrangentes, a ênfase recai sobre questões socioambientais amplas, como o combate ao racismo, a valorização da cultura popular, a preservação ambiental e a sustentabilidade. Essa diversidade de abordagens denota que as ações socioeducativas podem incidir sobre diversos aspectos, exigindo, dessa forma, orientações específicas, relacionadas às singularidades das atividades físicas e esportivas de cada projeto.

Ao identificarmos as especificidades de cada projeto, uma das principais fragilidades encontradas nos documentos analisados é de natureza procedimental e está circunscrita na imprecisão de como as atividades físicas e esportivas serão trabalhadas 
para atingir os objetivos propostos. Em relação a esse aspecto, a Instituição D foi a que mais se aproximou de um detalhamento dos modos como essas devem se desenvolver. Apesar do potencial educativo de tais atividades, a falta de um delineamento pedagógico no desenvolvimento de suas práticas, com procedimentos bem definidos, pode dificultar o alcance dos objetivos desejados e, em alguns casos, até produzir resultados contrários ao que se pretende.

Ações afirmativas de natureza socioeducativa, desenvolvidas no campo da pedagogia social, precisam ser legitimadas em um país que busca a equidade entre os seus cidadãos. Essa legitimação perpassa por processos complexos, que vão desde a normatização e a legalização desse campo de trabalho, do reconhecimento profissional de seus agentes, até a questões mais específicas e pontuais, como a sistematização de processos pedagógicos que ocorrem no interior de cada projeto social e de ações socioeducativas específicas. Nesse processo de sistematização, o investimento na formulação de documentos orientadores, aqui denominados de currículos prescritos, é uma importante ação para qualificar os processos pedagógicos desenvolvidos em diferentes contextos sociais.

\section{REFERÊNCIAS}

AAOCA (Associação de Apoio e Orientação à Criança e ao Adolescente). Estatuto social, Vila Velha, 2017.

ACDASCC (Associação Cultural Desportiva e de Ação Social Capoeira na Comunidade), Estatuto social, Vitória, 2018.

BLOCH, M. L. J. Apologia da história: ou, o ofício do historiador. Rio de Janeiro: Zahar, 2001.

BRASIL, Ministério de Desenvolvimento Social e Combate à Fome. Secretaria Nacional de Assistência Social. Tipificação Nacional de Serviços Socioassistenciais. Brasília, 2014. 
BRASIL, Ministério de Desenvolvimento Social e Combate à Fome. Secretaria Nacional de Assistência Social. Orientações técnicas sobre o serviço de convivência e fortalecimento de vínculos para crianças e adolescentes de 6 a 15 anos. Brasília, 2010.

CARDOZO, G. C. de S. Educação de jovens e adultos e educação social: reflexões sobre o componente (re)instituidor de direito das medidas socioeducativas. In: MULLER, V. R. (org.). Pedagogia social e educação social: reflexões sobre as práticas educativas no Brasil, Uruguai e Argentina. Curitiba: Appris, 2017. p. 135-148.

CARON, A. E. G.; MARCHI JUNIOR, W.; SILVA, M. M. O mapeamento da produção científica sobre projetos esportivos no Brasil. Licere, Belo Horizonte, v. 21, n. 2, p. 26 49, jun. 2018. DOI: https://doi.org/10.35699/1981-3171.2018.1809.

COSTA, R. S. O.; SILVA, C. A. F.; VOTRE, S. J. Educação física, esporte e desenvolvimento sustentável. Pensar a Prática, Goiânia, v. 14, n. 1, p. 1-14, jan./abr. 2011.

DACOSTA, L. Educação Olímpica como metalinguagem axiológica: revisões pedagógicas e filosóficas de experiências internacionais e brasileiras. In: REPPOLD, A. et al. Olimpismo e educação olímpica no Brasil. Porto Alegre: Editora da UFRGS, 2009. p. 17-28.

HALL, S. A identidade cultural na pós-modernidade. Rio de Janeiro: DP\&A, 2005.

IVOS (Instituto Vila Olímpica Social) Estatuto social. Serra: [s.n.], ago. 2017.

KISIL, R. Elaboração de projetos e propostas para organizações da sociedade civil. Coleção Gestão e Sustentabilidade. São Paulo: Global, 2001.

KRAVCHYCHYN, C.; OLIVEIRA, A. A. B. Projetos e programas sociais esportivos no Brasil: uma revisão sistemática. Movimento, Porto Alegre, v. 1, n. 4, p. 1051-1065, out./dez. 2015.

LOPES, A. C.; MACEDO, E. Teorias de currículo. São Paulo: Cortez, 2011.

MAGRO, V. M. M. Adolescentes como autores de si próprios: Cotidiano, educação e o hip-hop. Cadernos CEDES, Campinas, v. 22, n. 57, p. 63-75, ago. 2002.

MELlO, A. S. et al. Atividades físicas e esportivas nos projetos sociais: o estado do conhecimento em revistas científicas da educação física. Licere, Belo Horizonte, v. 19, n. 4, dez. 2016. DOI: https://doi.org/10.35699/1981-3171.2016.20052.

MULlER, V. R. Pedagogia social e educação social: reflexões sobre as práticas educativas no Brasil, Uruguai e Argentina. Curitiba: Appris, 2017.

NALINI, J. R. Ética geral e profissional. 7. ed. São Paulo: Editora Revista dos Tribunais, 2009.

NASCIMENTO, G. S. et al. O serviço social na proteção social básica - Serviço de Convivência e Fortalecimento de Vínculos. Revista Direito em Foco, Amparo/SP, n. 11, p. 22-30, 2019. 
PEREIRA, J. N. A compreensão do ethos diante de normas morais e religiosas. Horizonte, Belo Horizonte, v. 3, n. 6, p. 33-46, jan./jun. 2005.

PIAGET, Jean. O juízo moral na criança. São Paulo: Summus Editorial, 1994.

RIBEIRO, L. Projetos de cidadania: uma leitura de iniciativas de participação social em favela paulista. 2008. Dissertação (Mestrado em Psicologia) - Programa de PósGraduação em Psicologia, Universidade de São Paulo, São Paulo, 2008.

SEABRA, S. L. P.; ROSSETTI, C. B. Aspectos cognitivos e morais do desenvolvimento infantil: investigação por meio de um conto de fadas em versão multimídia. Revista Construção Psicopedagógica, São Paulo, v. 24, n. 25, p. 133-148, 2016.

SACRISTÁN, J. G. O currículo como confluência de práticas. In: SACRISTÁN, J. G. (org.). O currículo: uma reflexão sobre a prática. 3. ed. Porto Alegre: Artmed, 1998. p. 101-106.

SACRISTÁN, J. G. O currículo: uma reflexão sobre a prática. Porto Alegre: Artmed, 2000.

SACRISTÁn, J. G. Saberes e incertezas sobre o currículo. Porto Alegre: Penso, 2013.

SODRÉ, M. Capoeira e Identidade. In: SILVA, J. E. de S. (org.). Esporte com Identidade Cultural. Brasília: Instituto Nacional de Desenvolvimento do Desporto, 1996. p. 68-81.

SOUZA, C. R. T. Educação Social e Avaliação: Indicadores para contextos educativos diversos. 2016, Tese (Doutorado em Educação), Universidade Estadual de Maringá, Maringá, 2016.

STOER, S. R.; MAGALHÃES, A. M.; RODRIGUES, D. Os lugares da exclusão social: um dispositivo de diferenciação pedagógica. São Paulo: Cortez, 2004.

THOMAS, J.; NELSON, J. Métodos de pesquisa em atividade física. 5. ed. Porto Alegre; Artmed, 2007.

ZALUAR, A. Cidadãos não vão ao paraíso: juventude e política social. Rio de Janeiro: Escuta, 1994.

\section{Endereço dos(as) Autores(as):}

Cássia dos Santos Gonçalves

Endereço Eletrônico: cassia.sg.dance@hotmail.com

Rodrigo Lema Del Rio Martins

Endereço Eletrônico: rodrigodrmartins@ufrrj.br

André da Silva Mello

Endereço Eletrônico: andremellovix@gmail.com 